\title{
PROFILE: JESSICA COTTIS
}

Conductor Jessica Cottis is Principal Conductor of the Glasgow New Music Expedition and maintains a busy schedule as a guest conductor worldwide. She came to international attention in 2011 after stepping in at short notice to conduct the premiere of James Dillon's Nine Rivers cycle with the BBC Scottish Symphony Orchestra and Les Percussions de Strasbourg and has gone on to conduct numerous premieres with orchestras such as BBC Symphony Orchestra, LPO, Sydney Symphony, Bit20

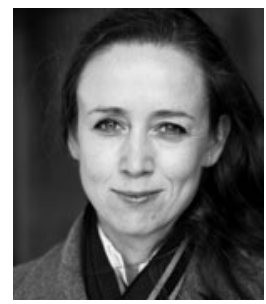

Jessica Cottis (photo: credit Tommy Ga-Ken Wan) Ensemble Bergen, RTV Slovenia Symphony Orchestra, and l'Orchestre Philharmonique de Monte-Carlo. Formerly an organist (having studied and worked in London and Paris), a hand injury halted her playing career and, after a year reading law, she began conducting studies at the Royal Academy of Music where she was awarded the top conducting prizes upon graduation in 2009. She was Assistant Conductor at the BBC Scottish Symphony Orchestra (2009-2011) and Sydney Symphony (2012-14).

Q. You conduct such a broad range of repertoire: what attracts you to new music?

A. I have wide-ranging musical passions ... it's safe to say I'm massively attracted to almost all classical music. On a daily basis I might be thinking about Bruckner or Bach, Bernstein or Birtwistle. But there's a special thrill of bringing a new piece to life, being part of something that is in essence a living and breathing organism.

I'm fascinated by sound as an entity. And new music can also be an endless intellectual fascination. Conducting it always guides me to discover anew the relevance, excitement and sense of adventure of the music of the past. It's as though Beethoven and Brahms and the rest become again the music of the present.

Q. Two recent projects caught my eye: your weekend workshop on contemporary music for Morley College's programme for women conductors, and Glasgow New Music Expedition. I have the impression you are a strong advocate for these causes! Can you tell us about these projects?

A. I'm hugely behind both these projects! GNME is an ensemble dedicated predominantly to performing music by living Scottish composers. It was born out of a desire to get more deeply into the venous system of the new music scene here, with a particular focus on young Scottish-based or Scottish-trained composers. The group itself consists of 12 hand-picked brilliant young instrumentalists - most are in their twenties - all Glasgow-based and all fiercely committed to performing new music in this country.

It is an amazing time in the history of Scotland and the creative energy is palpable. For me it's really important to commission Scottish composers - there's so much talent here. Already there's an impressive amount of new music-making going on (Ilan Volkov's brilliant 
Tectonics, for instance) but for those less-established composers there are few opportunities for their music to be heard, shared, discussed, challenged and reflected upon. It became clear to me that there is requirement for this type of initiative and through GNME we're dedicated to filling that gap: it's both incubator and laboratory. Our programmes are untested, but that's the point: there's a danger with any artistic institution if they feel they have to play safe. We have a collective vision in that we want to nurture emerging composers and give them the opportunities needed. And there's a feeling that we're all involved in something bigger than ourselves. It's not exactly that we're being part of a movement, but it's part of being the historical bloodline of a culture.

Our events aren't supposed to be easy for our listeners, for the players, or for me as conductor. There's always a hook for our audiences though, and all but one of our performances over the last year have been sold out. I've noticed already some tropes coming through in our programming: one is interplanetary science. Co-artistic director/composer Richard Greer and I are interested in all things to do with outer space; using the word 'Expedition' was born of this. The concept of exploring new worlds, new frontiers, is of course central to our vision. Most recently we premiered a piece by Jay Capperauld that took its inspiration from the idea that Yuri Gagarin actually wasn't the first person to venture successfully into space. I was required to conduct at crotchet $=7.5$ with no subdivisions, 'as though in zero gravity'. Everyone became very zen!

The Women Conductors at Morley courses are something really special. I recently spent an intensive weekend working with a group of composers and budding conductors, all interested in learning about many of the different skills needed to conduct new music. There are very few prominent female composer-conductors today and I was struck by how odd this is. Here was a group of competent and intelligent young women, keen to learn, yet for the most part lacking in confidence. After some intense sessions, the results far exceeded expectations, with all the participants making huge breakthroughs, either technically or personally. The RPS [Royal Philharmonic Society] will now take over the running of these courses and, excitingly, even greater plans lie ahead. One day courses such as this will be unnecessary, anachronistic even; for now at least, they remain of crucial importance. Talent and creativity know no gender, and these courses go some way to addressing and enabling this.

Q. Who are your new music heroes?

A. There are so many incredible musicians and thinkers whom I could list! Messiaen was the first 'contemporary' composer who fascinated me. One of the first CDs I bought was the Argerich/Rabinovitch recording of Visions de l'Amen, which thrilled with each and every listening. There's also Richard Meale: he introduced the avant-garde movement to my birth country, Australia, and made an inestimable contribution to the new music scene there, conducting first performances of works by Boulez, Bussotti, Messiaen and Schoenberg (including the first Australian performance of Pierrot Lunaire ... in 1959!). Incredible Floridas, his musical homage to Rimbaud made in collaboration with filmmaker Peter Weir, is stunning. The great conductor-composer Bruno Maderna also makes my list, as does polymath Xenakis: the shocking otherness of Synaphaï, for example, is breathtaking. 
Q. Which piece of art (of any media) has most affected you recently? A. Outside of music I'm a visual art obsessive. It is always a delight to tour somewhere new as it means more art galleries to explore. A piece that's remained at the forefront of my mind lately is Roy de Maistre's Rhythmic composition in yellow green minor, painted in 1919, and now on permanent display at the NSW Gallery of Art in Sydney. De Maistre is notable in that he produced Australia's first abstract paintings, devised through a new colour theory that he based on the affinities between sections of the colour spectrum and notes of the musical scale.

This painting, which is alternatively (and rather gloriously) titled Frozen Music, is the only documented example remaining from his 1919 'Colour in Art' exhibition with fellow artist Roland Wakelin. Comprising 11 paintings and five interior decoration schemes, including rooms in 'Blue Green Major' and 'Yellow Green Minor', the exhibition attracted a crowd of 700 to the opening and was highly controversial. Although the press and public were enthralled - these were 'pictures you could whistle to' - the conservative establishment condemned de Maistre's modernist tendencies.

Seen live, the emotional impact is surprisingly shocking. The initial impulse is to listen: it's almost as if you can hear the interweaving sinuous curves emitting distinct musical phrases, with the large areas of flat paint and simplified swirling forms moving as if in harmony with each other. De Maistre studied violin at the Sydney Conservatoire as a young man, and anecdotally it is said that Beethoven's String Quartet op. 131 was his inspiration.

Q. Is there a project you are dreaming about creating?

A. New projects are constantly percolating, especially around the concept of music as cultural diplomacy. I'm reminded of Tolstoy's polemic in What is Art?: 'Art is a means of union among men, joining them together in the same feelings, and indispensable for the life and progress toward well-being of individuals and of humanity'. 